\title{
An experimental study on stress-strain behavior and constitutive model of hardfill material
}

\author{
WU MengXi ${ }^{1 *}$, DU Bin ${ }^{1}$, YAO YuanCheng ${ }^{2} \&$ HE XianFeng ${ }^{3}$ \\ ${ }^{1}$ Key Laboratory of Environmental Mechanics, Institute of Mechanics, Chinese Academy of Sciences, Beijing 100190, China; \\ ${ }^{2}$ Guiyang Hydropower Investigation Design \& Research Institute, CHECC, Guiyang 550081, China; \\ ${ }^{3}$ Yellow River Institute of Hydraulic Research, Zhengzhou 450003, China
}

Received March 8, 2011; accepted June 7, 2011; published online September 27, 2011

\begin{abstract}
Hardfill is a new type of artificially cemented material for dam construction works, with a wide application prospect. Its mechanical behavior lies between concrete and rockfill materials. A series of large-scale triaxial tests are performed on hardfill specimens at different ages, and the stress-strain behavior of hardfill is further discussed. The strength and stress-strain relationship of hardfill materials show both frictional mechanism and cohesive mechanism. An age-related constitutive model of hardfill is developed, which is a parallel model consisting of two components, rockfill component and cementation component. Moreover, a comparison is made between the simulated and the experimental results, which shows that the parallel model can reflect the mechanical characteristics of both rockfill-like nonlinearity and concrete-like age relativity. In addition, a simplified method for the determination of parameters is proposed.
\end{abstract}

hardfill, stress-strain relationship, large-scale triaxial tests, constitutive model

PACS: 83.60.-a, 62.20.-x, 81.05.Zx

\section{Introduction}

Hardfill [1] is a new type of artificially cemented material for dam construction, produced by adding low content cementitious material and water to rock based materials such as riverbed gravel or excavation muck, and mixing them with a simple device. Hardfill dam is mainly built by hardfill materials, with a symmetrical cross section and a watertight upstream face. The main advantages of this Faced Symmetrical Hardfill Dam (FSHD) are: low compressive and shear strength requirements, capability of water overtopping both during and after construction, capability of construction on weak foundations, reduced cement requirements which result in reduced unit costs compared with Roller Compacted Concrete (RCC) dams, a more relaxed specification for aggregates including grading requirements,

*Corresponding author (email: wumx@imech.ac.cn) excellent seismic resistance, little or no requirement for joint preparation between placed layers, and so on [1-3]. The total cost of FSHD may be lower than that of a conventional section RCC gravity dam [4]. In the past twenty years, more than ten FSHDs [5-11] have been constructed or still under construction throughout the world. The heights of these FSHDs mainly range from $30 \mathrm{~m}$ to $60 \mathrm{~m}$, with the highest $107 \mathrm{~m}$ Cindere dam [7] in Turkey. Besides, due to the rapid construction velocity and water over-topping capability, temporary hardfill constructions such as cofferdams and checkdams [12] are widely used. In recent years, FSHD has attracted more attention in China. Up to now, five hardfill cofferdams [13-16] have been constructed, with the first in 2004. With the development of hydropower in China, the safe, economical and environment-friendly hardfill dam may enjoy broad prospects of application.

The mechanical properties of hardfill material are similar to that of rockfill material before being hardened, while the 
strength and deformation modulus of the hardened hardfill are much greater. The mechanical behavior of hardfill material falls in an intermediate area between concrete and rockfill materials. This behavior is governed, on the one hand, by the friction between the grains, and on the other hand, by the bonds between the grains due to cementation. Therefore one can consider hardfill material as a cohesive-frictional material. Recently, there are two different research routes to the constitutive model, one from concrete viewpoint, and the other from geotechnical viewpoint. Hardfill material can be handled as a lean RCC material [17] with linear elastic modulus from the concrete viewpoint, whereas it can be handled as a cemented rockfill material with nonlinear stress-strain relationship from the geotechnical viewpoint. The mechanical behavior of the material may not be properly described just from one perspective separately. Further understanding and appreciation of the mechanical behavior and development of the constitutive model of the material are the bases for design techniques of FSHD. In this paper, a series of large-scale triaxial shear tests are performed on hardfill specimens at different ages, and an age-related constitutive model of hardfill will be developed, which can reflect the mechanical characteristics of both rockfill-like nonlinearity and concrete-like age relativity.

\section{Experimental study on stress-strain behavior of hardfill material}

The concept of hardfill comes from the improvement of RCC dams. Transforming the shape of gravity dams with symmetrical slopes can decrease the strength requirement of the architectural material, and then the cement content can be low. Because of the lower requirement of material strength, specification for aggregates used in hardfill dams can be relaxed. Even raw excavated material or sand-gravel material can be utilized, whose mechanical property is lower than normal concrete aggregates [1]. The cement content of hardfill materials is generally no more than 90 $\mathrm{kg} / \mathrm{m}^{3}$ [5]. Thus, the properties of hardfill are different from that of conventional concrete.

The stress-strain curve of hardfill at the age of $28 \mathrm{~d}$ obtained by the uniaxial compression test $[18,19]$ is similar to that of conventional concrete. It can be divided into three ranges. The first range can be approximated to be linear, named "linear range", and the maximum stress in the linear range is defined as "linear limit strength"; the curve of the second range is non-linear and ends with a peak point which is named peak strength; in the third part the sample starts to break and the stress goes down. In cyclic loading tests $[18,19]$, the elasto-plasticity clearly appears and the residual strain increases cumulatively when a cyclic load exceeds the linear limit strength. Hardfill is a typical elasto-plasticity material [18-20].
Uniaxial compression tests $[3,14,21]$ of hardfill material at different ages show that there is concrete-like age relativity of mechanical behavior. The strength and modulus of hardfill increase with the curing time, similar to that of the conventional concrete, whereas the strength of hardfill still increases apparently after 28 days as shown in Figure 1. In order to reduce the cement content and lower the hydration heat further, fly ash is often used in hardfill to replace some cement. The hydration reaction of fly ash (also named Pozzolanic reaction) is a secondary reaction between fly ash and $\mathrm{Ca}(\mathrm{OH})_{2}$ generated by cement hydration. Pozzolanic reaction is much slower than the initial hydration process of cement. Therefore, the development of hardfill's strength is much slower, the later-age strength will be relatively great [22].

So far, the experimental study of hardfill material by triaxial shear tests [23-27] has been done either at a single age or under a single confining pressure. In the triaxial tests, the relationship between the stress difference $\left(\sigma_{1}-\sigma_{3}\right)$ and axial strain $\varepsilon_{1}$ is non-linear, and it shows a strain softening characteristic. Confining pressures affect the stress-strain curves and volumetric strain curves of hardfill material apparently.

For further discussion on the mechanical behavior of hardfill material at different ages and the effects of cementation, three groups of large-scale triaxial shear tests are performed. The specimens of the first group are made of rockfill without any cementitious material, which represent the initial conditions of hardfill material before being hardened. The other two groups are hardened hardfill specimens of 7-day age and 28-day age, respectively. These three groups have the same aggregate gradation and dry density $\left(2.17 \mathrm{~g} / \mathrm{cm}^{3}\right)$. The specimens of the second and third groups have the same content of cementitious material and water-cement ratio.

\subsection{Test method}

The original material used by rockfill specimens is sandy gravel from the Gobi desert. The maximum grain size is limited within $60 \mathrm{~mm}$ as shown in Figure 2. Hardfill specimens are made of rockfill material by adding cement and fly ash. There are $40 \mathrm{~kg}$ cement of 425\#, $60 \mathrm{~kg}$ fly ash and 70 $\mathrm{kg}$ water mixed per cubic meter of hardfill. All cylindrical

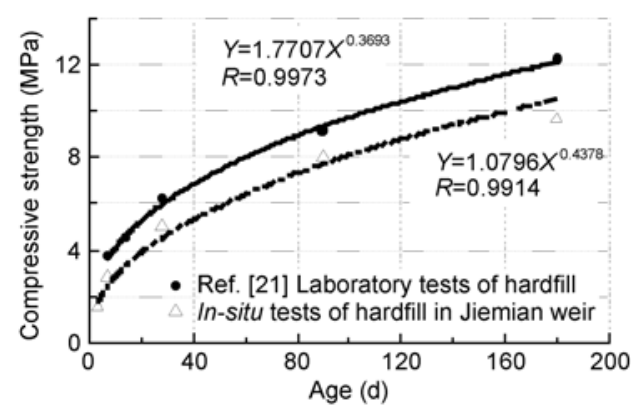

Figure 1 The growth curves of strength [14,21]. 


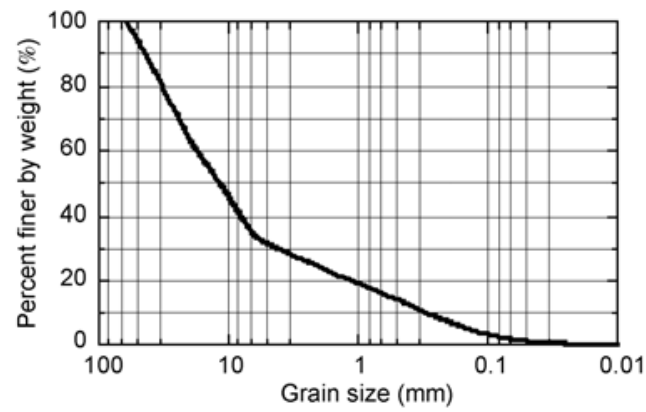

Figure 2 Grain size distribution of the rockfill material.

specimens are $30 \mathrm{~cm}$ in diameter, and $70 \mathrm{~cm}$ high. Besides, the specimens of hardfill material are kept for $7 \mathrm{~d}$ or $28 \mathrm{~d}$ in ambient temperature and humid condition.

All triaxial tests are carried out under saturated consolidated drained (CD) conditions. There are four specimens in each group. The specimens are consolidated respectively under constant confining pressures 200, 400, 600 and 800 $\mathrm{kPa}$ with the same consolidation ratio $\left(K_{c}=1\right)$. Loads in the axial direction are applied with the velocity of $0.02 \mathrm{~mm} / \mathrm{s}$ after consolidation completed. Axial load, displacement and water discharge are all recorded automatically by a computer during the test process. The test should be stopped while the specimen is totally destroyed or the value of axial strain reaches $15 \%$.

\subsection{Results and analysis of laboratory tests}

The stress-strain curves of rockfill and hardfill specimens are shown in Figure 3.

Figure 3 shows: (i) The stress-strain curves of rockfill specimens are approximate to hyperbola, and there are no apparent peak stress. (ii) The specimens of hardfill have obvious peak stresses. The stress difference $\left(\sigma_{1}-\sigma_{3}\right)$ increases with axial strain $\varepsilon_{1}$ before the peak, while the gradient decreases. The range around the peak stress shows the non-linear relation of stress and strain apparently. Axial strain still increases after the peak strength, but stress difference gradually decreases, which shows the strain softening characteristic, stress difference gradually tends to a certain residual strength. Moreover, the greater the confining pressure is, the greater the residual strength is. The stressstrain characteristics of hardfill coincide with the triaxial tests of 28-day hardfill performed by SUN and his colleagues [27]. (iii) The strain softening will become more apparent, when the age is getting older. (iv) With the age increasing, the peak strength and initial modulus of hardfill increase. The axial strain corresponding to peak strength is relatively small. Compared with rockfill, the strength and initial deformation modulus of hardfill have substantial increments. When the confining pressure is low, the cementitious material apparently improves the strength of hardfill in particular.
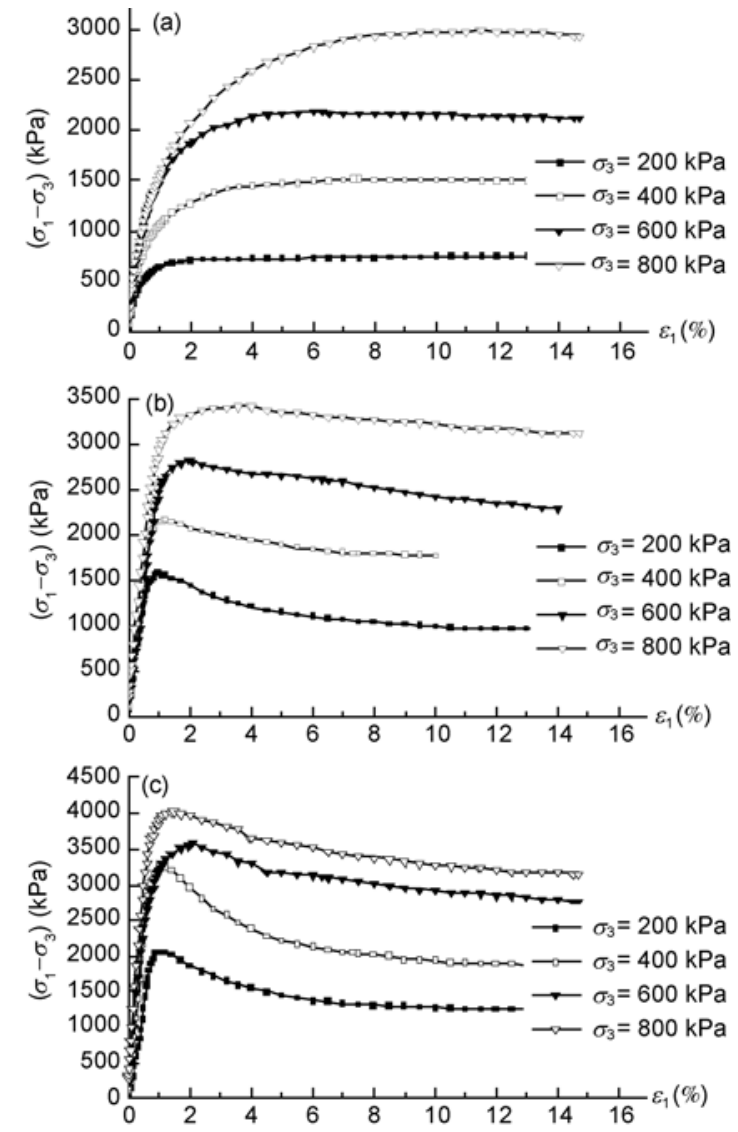

Figure 3 Stress-strain curves of the hardfill at different ages. (a) Rockfill; (b) $7 \mathrm{~d}$ hardfill; (c) $28 \mathrm{~d}$ hardfill.

In the stress-strain curve, the peak stress can be taken as failure strength; if there is no peak strength, stress corresponding to $\varepsilon_{1}=15 \%$ can be taken as failure strength. And then according to Mohr circles of failure strength under different confining pressures, the failure strength envelope can be plotted. In the same way, the residual strength envelope can also be drawn. As to both rockfill and hardfill, the results show that the failure and residual strength envelopes are all straight lines. Mohr circles and envelopes of $28 \mathrm{~d}$ hardfill are plotted in Figure 4 as an example. All of MohrCoulomb strength parameters are listed in Table 1.

It can be concluded from Table 1 that cohesion values of

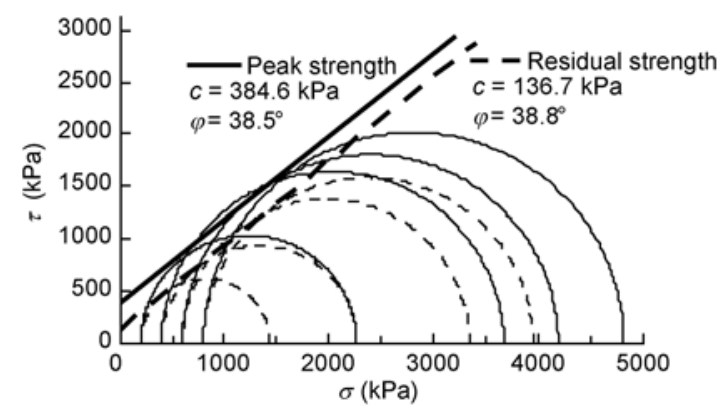

Figure 4 Mohr circles of $28 \mathrm{~d}$ hardfill. 
Table 1 Mohr-Coulomb strength parameters

\begin{tabular}{ccccc}
\hline \multicolumn{2}{c}{ Strength parameter } & Rockfill & Hardfill (7 d) & Hardfill (28 d) \\
\hline \multirow{2}{*}{ Peak } & $c(\mathrm{kPa})$ & 4.2 & 236.4 & 384.6 \\
& $\varphi\left({ }^{\circ}\right)$ & 40.4 & 37.3 & 38.5 \\
\multirow{2}{*}{ Residual } & $c(\mathrm{kPa})$ & 8.7 & 67.1 & 136.7 \\
& $\varphi\left({ }^{\circ}\right)$ & 39.9 & 39.5 & 38.8 \\
\hline
\end{tabular}

hardfill varies with age apparently, whereas friction angle $\varphi$ varies little. These features coincides with the relevant tests results [15] of the Hongkou hardfill cofferdam in Fujian province and tests [28] of Takizawa dam in Japan. The residual cohesion of hardfill decreases substantially compared with the peak cohesion. The residual value of $7 \mathrm{~d}$ hardfill is about $28 \%$ of the peak value, while the $28 \mathrm{~d}$ is about $36 \%$. Nevertheless, the residual friction angle is close to the peak strength friction angle.

The curves of axial strain-volumetric strain of rockfill and hardfill specimens are shown in Figure 5. According to the results, there is a shear dilation phenomenon for rockfill specimen under the confining pressure $200 \mathrm{kPa}$ only, whereas all the hardfill specimens for age $7 \mathrm{~d}$ and $28 \mathrm{~d}$ show dilation except the specimen for age $7 \mathrm{~d}$ with confining pressure $800 \mathrm{kPa}$. The dilation tends to happen more easily with the age increasing. Besides, the axial strain corre-
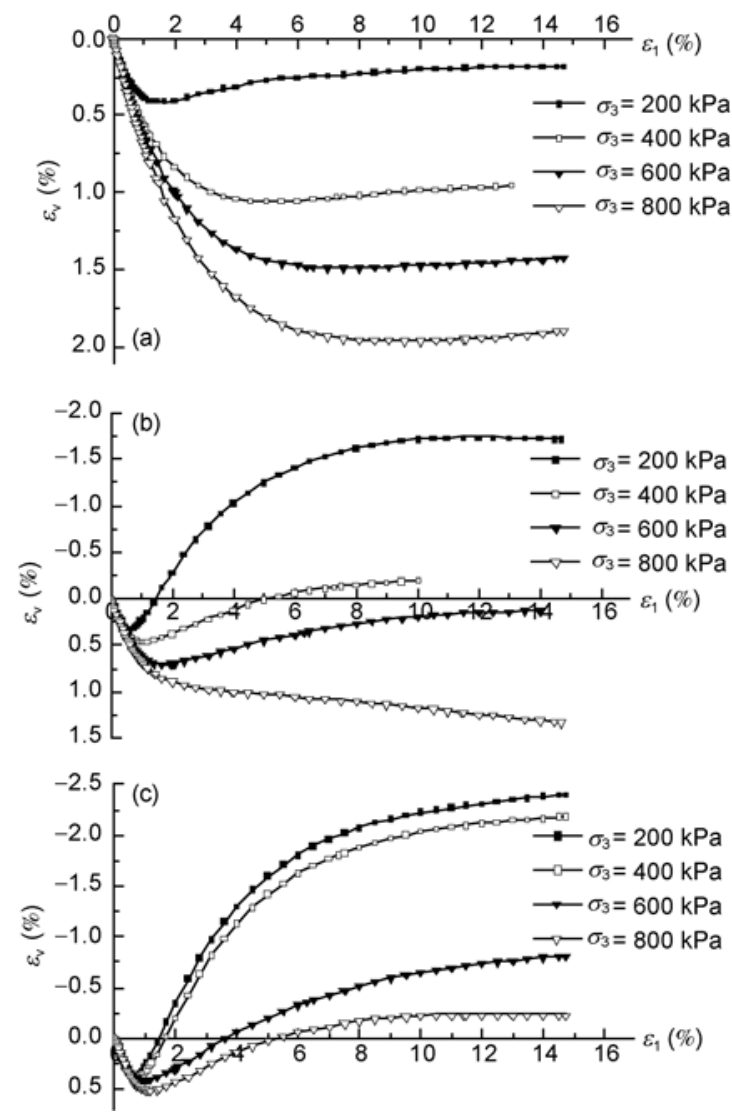

Figure 5 Curves of the volumetric strain: (a) rockfill; (b) 7 d hardfill; (c) 28 d hardfill. sponding to the initial dilation point gradually decreases with the age, and the maximum compressive volume also decreases gradually under high confining pressures.

\subsection{Effect of cementation on stress-strain relationship}

These three group specimens have the same aggregate gradation and dry density. The rockfill group represents the initial condition of hardfill material before its hardening, and the other two groups are the hardened hardfill respectively at 7-day age and 28-day age. The difference of curves between rockfill and hardfill specimens reflects the effect of cementation. Influence curves of deviatoric stress difference and volumetric strain difference are shown in Figures 6 and 7 , respectively.

In Figure 6, the curves at the beginning show apparent linear increasing characteristic; after the peak, the curves fall quickly; the effects of the age on stress-strain curves are significant. The slope of the linear range of curves in Figure 6 represents the influence of cementation to the modulus of hardfill. Comparing Figure 6(a) with Figure 6(b), it can be found that the slope of $28 \mathrm{~d}$ hardfill is much steeper than that of $7 \mathrm{~d}$ hardfill, indicating that the shear strength and modulus of hardfill increase gradually with age. In Figure 7, when the axial strain is small $\left(\varepsilon_{1}<1 \%\right)$, the amplitude of volumetric strain difference is less than one ten-thousandth, less than $5 \%$ of the total volumetric strain of hardfill, and it can be considered that cementation does not influence the curves of axial strain - volumetric strain in this range approximately. However, the effect of cementation on volumetric strain curve is remarkable after this range, mostly showing apparent dilation.
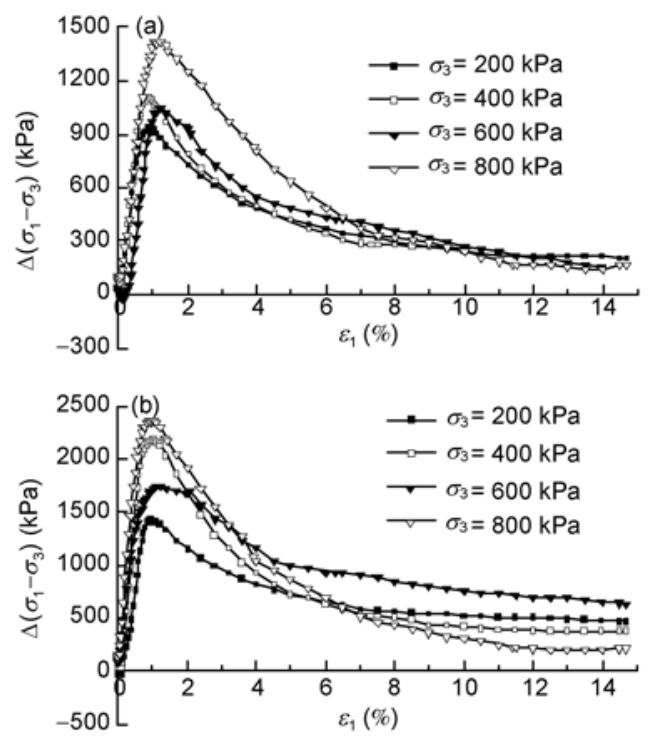

Figure 6 Influence curves of the deviatoric stress difference. (a) $7 \mathrm{~d}$ influence curves by subtracting Figure 3(a) from Figure 3(b); (b) $28 \mathrm{~d}$ influence curves by subtracting Figure 3(a) from Figure 3(c). 

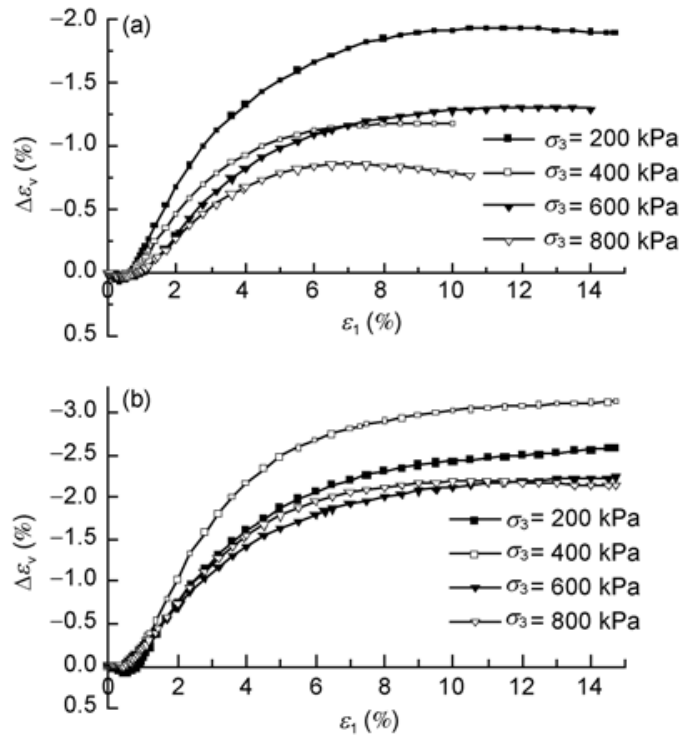

Figure 7 Influence curves of the volumetric strain difference. (a) $7 \mathrm{~d}$ influence curves by subtracting Figure 5(a) from Figure 5(b); (b) $28 \mathrm{~d}$ influence curves by subtracting Figure 5(a) from Figure 5(c).

\section{Constitutive model of hardfill material}

\subsection{Development of constitutive model of hardfill ma- terial and conceptual modelling}

Constitutive models of hardfill material can be generally classified into linear and nonlinear models according to the published relevant papers.

Fujisawa, Hirose and their coworkers [18,19] indicated that the linear strength and the modulus of elasticity in the linear range should be used as material properties of hardfill, according to the results obtained by uniaxial compression tests and cyclic loading tests. Li et al. [29] put forward a continuum equivalent model to simulate the stratified structure of hardfill dam, in view of the weak joint surfaces between layers.

Large-scale triaxial tests show that stress-strain curves of hardfill material are nonlinear, significantly influenced by confining pressures. Li et al. [26] suggested that hyperbolic model could be used to describe the nonlinear stress-strain relationship. The hardfill material shows a strain softening behavior when the peak of its stress-strain curve is reached. On account of the fact, Sun et al. [30] developed a constitutive model with the softening characteristics by use of the virtual rigid spring method, and determined the parameters for the model.

Note should be taken that Chazallon and Hicher [31] constructed a useful generic constitutive model of bonded geomaterials, such as aged clay, marls, sandstones and artificially cemented geomaterials, by combining two single models (i.e., two components) which contain two grainscale mechanisms. The first mechanism deals with friction between grains, which can be described by any of the suitable existing models of the uncemented soil. The second mechanism, linking the behavior of the bonds between grains and their damage with strain, can be modelled separately, e.g., by the elastic model with damage. Vatsala et al. [32] proposed a model that is conceptually similar, but their treatment of the bond component is different, being an elastoplastic model.

Hardfill material is an artificially cemented geomaterial, which can be classified as a bonded geomaterial. Thus, these constitutive models of bonded geomaterials may be applied after adaption. Note that cementation of the hardfill material is so age-related as to be taken into consideration when constitutive modeling is represented, which is not included in the above published models.

\subsection{Parallel model of two components}

The hardfill can be generalized as a combination of two components, rockfill component and cementation component. The rockfill component represents the conventional rockfill material without cementation, which reflects the influence of rockfill by playing a role of skeleton of this cement-rockfill mixture. The stress-strain curves of rockfill are plotted in Figure 3(a), which can be considered as the initial conditions of hardfill material before hardening. The cementation component characterizes the impact of cementation, with curves shown in Figure 6. Owing to the concrete-like age relativity of hardfill's strength and deformation modulus, the cementation component should be age-related. Once the relationship between the cementation component and the age is established, the combination model of the two components, rockfill and cementation will reflect the stress-strain features at different ages.

From the viewpoint of component, the analysis in sect. 2.3 is based on the parallel hypothesis of the two components, that is, strains of the two components are the same, and stresses are undertaken by the two separately, as shown in Figure 8.

Due to the parallel relation, both stresses and moduli of the two components can be added together directly. The cementation component may have influence on the total volume variation to some extent, so that it will affect the total Poisson's ratio. This effect can be generalized as an extra item added to the Poisson's ratio of rockfill component. The modulus and Poisson's ratio of the total could be computed as shown:

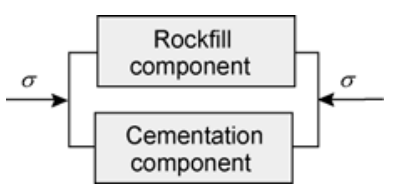

Figure 8 Parallel model of the two components. 


$$
\left\{\begin{array}{l}
E_{\mathrm{tt}}(\tau)=E_{\mathrm{rk}}+E_{\mathrm{cmt}}(\tau), \\
v_{\mathrm{ttl}}(\tau)=v_{\mathrm{rk}}+v_{\mathrm{ef}}(\tau),
\end{array}\right.
$$

where $E_{\mathrm{tt}}$ is the total modulus; $E_{\mathrm{rk}}$ is the modulus of rockfill component; $E_{\mathrm{cmt}}$ is the modulus of cementation component; $v_{\text {ttl }}$ is the total Poisson's ratio; $v_{\mathrm{rk}}$ is the Poisson's ratio of rockfill component; $v_{\text {ef }}$ is the additional item of Poisson's ratio; $\tau$ is the age of hardfill material.

According to the above conceptual model of hardfill material, rockfill component is made up of the conventional rockfill without cementation. Thus, this rockfill component can be used under nonlinear constitutive models of soil, such as Duncan-Change hyperbolic model or uncoupled $\mathrm{K}-\mathrm{G}$ model, which are widely used in the analysis of embankment stresses and deformations in China. Meanwhile, the cementation component can use an age-related damage model.

\subsection{Strength criterion}

The analysis in sect. 2.2 indicates that the failure strength of hardfill material follows the Mohr-Coulomb strength theory; that friction angle $\varphi$ varies little with age, whereas the cohesion $c$ increases with age. Thus, the strength criterion can be written as:

$$
\tau_{f}=c(\tau)+\sigma \tan \varphi,
$$

where $\tau_{f}$ is the shear strength; $\sigma$ is the normal stress; $\tau$ is the age of hardfill material.

The expression of the cohesion $c(\tau)$ at different ages can be determined as a hyperbolic type, exponential type or power type according to the test results.

\subsection{Constitutive model and parameters of cementation component}

The elastic damage theory of cementation component with age-related feature can be proposed, referring to that of concrete. The stress-strain curves of $7 \mathrm{~d} / 28 \mathrm{~d}$ cementation component are plotted in Figure 6, showing a linear relation between deviatoric stress and axial strain at the initial stage. This stage can be determined as a undamaged stage. When the axial strain is getting larger, microcracks or fissures may be occur at bonds between particles and the secant gradient of the curve decreases. This is at the damage stage, where the features can be described after the introduction of damage variable. The stress-strain equation can be computed as follows:

$$
\sigma_{1}-\sigma_{3}=(1-\omega) \cdot E(\tau) \cdot \varepsilon_{1},
$$

where $\omega$ is the damage factor [33], regulating the cementation degradation evolution with stain; $\varepsilon_{1}$ is the axial strain; $E(\tau)$ is the undamaged elastic modulus as a function of the age of hardfill; $\tau$ is the age.
When the axial strain is no more than a certain strain, the cementation component is undamaged and the damage factor equals zero. When the axial strain is greater, it is at the damage stage and the damage factor lies between 0 and 1 . The certain strain written as $\varepsilon_{1 \mathrm{~d}}$ which separates these two stages is the so-called initial damage threshold of strain.

Thus, there will be several steps to determine the elastic damage model, shown mainly as follows: the determination of undamaged elastic modulus $E(\tau)$, the initial damage threshold $\varepsilon_{1 d}$ and the damage factor $\omega$.

\subsubsection{Determination of the undamaged elastic modulus}

The undamaged elastic modulus equals the slope of stress-strain curve of cementation component, which is related to the age, as shown:

$$
E(\tau)=f(\tau) \cdot E_{0},
$$

where $f(\tau)$ is an increasing function of the age; $E_{0}$ is a parameter showing the final elastic modulus of cementation component.

Based on the conceptual design of the parallel model, stresses are undertaken by two components respectively. Under uniaxial loading conditions, the cohesion of rockfill component is so small that the affordable stress of rockfill component is also small. Thus, most of the stress is undertaken by cementation component and the modulus obtained by uniaxial compression tests equals the modulus of cementation component approximately.

If the development trend of uniaxial compressive modulus at different ages is examined, the function $f(\tau)$ can be assumed as a complex exponential formula or a hyperbolic formula due to the experimental results. Zhu [34] indicated the complex exponential formula is better for the conventional concrete, and the hyperbolic formula is better for the RCC. Considering that the hardfill material is more similar to the RCC in terms of construction method and material composition, a simpler and more precise hyperbolic formula is chosen, as shown:

$$
f(\tau)=\frac{\tau}{M+\tau},
$$

where $M$ is a parameter related to the feature of the cementitious material of hardfill; $\tau$ (day) is the age of hardfill material.

Insert eq. (5) into eq. (4), and then eq. (6) is obtained:

$$
\frac{\tau}{E(\tau)}=\frac{M}{E_{0}}+\frac{\tau}{E_{0}} \text {. }
$$

By setting the age $\tau$ as the horizontal axis and $\tau / E(\tau)$ as the vertical axis, it may be noted that $M / E_{0}$ and $1 / E_{0}$ respectively are the intercept and the slope of the resulting straight line. By plotting modulus-age data in this form, it is easy to determine the values of the parameters $M$ and $E_{0}$ corre- 
sponding to the best fit between a hyperbola and the test data.

For these triaxial tests described above, the undamaged elastic moduli of $7 \mathrm{~d}$ and $28 \mathrm{~d}$ hardfill materials respectively are $160 \mathrm{MPa}$ and $240 \mathrm{MPa}$. The parameters determined from these results are $M=5.6, E_{0}=288 \mathrm{MPa}$.

\subsubsection{Determination of the initial damage threshold}

The linear range of stress-strain curve can be regarded as a undamaged stage. The initial damage threshold of strain is responding to the maximum axial strain in the linear range. The damage of cementation component occurs when the threshold is exceeded. The initial damage thresholds of axial strain at the age of $7 \mathrm{~d}$ and $28 \mathrm{~d}$ are listed in Table 2 . There is a correlation among thresholds, confining pressures and ages, which can be expressed as follows:

$$
\varepsilon_{1 d}=g\left(\sigma_{3}, \tau\right)
$$

in which $\varepsilon_{1 d}$ is the initial damage threshold of axial strain; $g$ represents the functional relationship.

Sun et al. [35] have shown that the correlation between the initial damage threshold of axial strain and the confining pressure can be approximated by an exponential expression. In consideration of the lack of laboratory study on the thresholds and uncertain expressions, an exponential function is assumed:

$$
\varepsilon_{1 d}=\alpha(\tau) \cdot \exp \left[\beta(\tau) \cdot \sigma_{3} / p_{a}\right],
$$

where $p_{a}$ is the atmospheric pressure; $\alpha(\tau)$ and $\beta(\tau)$ are parameters related to the age of hardfill material; $\tau$ is the age.

The parameters in eq. (8) determined from these tests were $\alpha(7)=0.28 \%, \beta(7)=0.12, \alpha(28)=0.32 \%$ and $\beta(28)$ $=0.13$. And the fitted values are listed in Table 2 , which can approximately reveal the correlation among thresholds, confining pressures and ages.

Functions $\alpha(\tau)$ and $\beta(\tau)$ can be determined by linear interpolation. When the age is other than $7 \mathrm{~d}$ and $28 \mathrm{~d}$, the values of the two might be set as at the age of $7 \mathrm{~d}$ or $28 \mathrm{~d}$.

\subsubsection{Determination of the damage factor}

At the damage stage, the damage factor $\omega$ is introduced into the stress-strain equation of cementation component. Damage factors corresponding to experimental results are plotted in Figure 9. It can be concluded that the damage factor is less affected by the confining pressure and the age. More-

Table 2 The Initial damage thresholds of axial strain

\begin{tabular}{cccccc}
\hline \multirow{2}{*}{$\begin{array}{c}\text { Effective } \\
\text { confining pressure }\end{array}$} & \multicolumn{2}{c}{$7 \mathrm{~d}$} & & \multicolumn{2}{c}{$28 \mathrm{~d}$} \\
\cline { 2 - 3 } \cline { 5 - 6 } & experimental & fitted & & experimental & fitted \\
\hline $200 \mathrm{kPa}$ & $0.35 \%$ & $0.35 \%$ & & $0.40 \%$ & $0.41 \%$ \\
$400 \mathrm{kPa}$ & $0.45 \%$ & $0.45 \%$ & & $0.55 \%$ & $0.53 \%$ \\
$600 \mathrm{kPa}$ & - & $0.57 \%$ & & $0.70 \%$ & $0.69 \%$ \\
$800 \mathrm{kPa}$ & $0.70 \%$ & $0.72 \%$ & & $0.85 \%$ & $0.89 \%$ \\
\hline
\end{tabular}

over, the damage factor increases with $\left(\varepsilon_{1}-\varepsilon_{1 \mathrm{~d}}\right)$. The fitting expression in exponential form is given by

$$
\omega=1-\exp \left[-Q \cdot\left(\varepsilon_{1}-\varepsilon_{1 \mathrm{~d}}\right)\right]
$$

in which $\omega$ is the damage factor, lying between 0 and $1, Q$ is a parameter.

The parameter $Q$ determined from these tests is 85 and the fitted line is also drawn in Figure 9.

\subsubsection{Effect of cementation component on the total Pois- son's ratio}

The effect of cementation component on the axial strain volumetric strain curves is shown in Figure 7 . When the axial strain is small or roughly below the threshold strain, it may be supposed that the cementation might not affect the total volumetric strain curve, i.e., the cementation might not affect the total Poisson's ratio. When the threshold strain is exceeded, the effects may cause significant dilation.

The effect of cementation on the Poisson's ratio of the material is generalized as an extra item added to the Poisson's ratio of rockfill. The mathematical expression of the extra item is assumed as a piecewise function shown as follows: when the axial strain is below the threshold strain, the cementation does not affect the total Poisson's ratio and the extra item equals zero; when it is above the strain, the extra item is not zero and relevant to some factors such as the confining pressure, axial strain, the age of hardfill material and so on.

For triaxial tests, $v=-\Delta \varepsilon_{3} / \Delta \varepsilon_{1}$ and $\Delta \varepsilon_{v}=\Delta \varepsilon_{1}+2 \Delta \varepsilon_{\mathrm{e}}$. Thus

$$
v=\frac{1}{2}\left(1-\frac{\Delta \varepsilon_{v}}{\Delta \varepsilon_{1}}\right)
$$

Substitute eq. (10) into eq. (1), and then

$$
v_{\mathrm{ef}}=-\frac{1}{2} \cdot \frac{\Delta\left[\left(\varepsilon_{v}\right)_{\mathrm{ttl}}-\left(\varepsilon_{v}\right)_{\mathrm{rk}}\right]}{\Delta \varepsilon_{1}}
$$

in which $\left(\varepsilon_{v}\right)_{\mathrm{ttl}}$ and $\left(\varepsilon_{v}\right)_{\mathrm{rk}}$ are respectively the volumetric strains of the total and the cementation components.

The item $\left[\left(\varepsilon_{v}\right)_{\mathrm{ttl}}-\left(\varepsilon_{v}\right)_{\mathrm{rk}}\right]$ in eq. (11) can be determined by

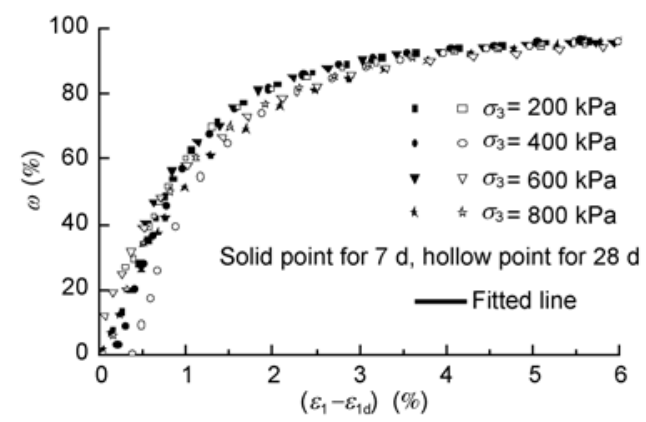

Figure 9 Relation between the damage factor and the $\left(\varepsilon_{1}-\varepsilon_{1 d}\right)$ of cementation component. 
subtracting the $\varepsilon_{1} \sim \varepsilon_{v}$ curve of rockfill from the one of hardfill, as shown in Figure 7 . The value of $\Delta\left[\left(\varepsilon_{v}\right)_{\mathrm{tt}}-\left(\varepsilon_{v}\right)_{\mathrm{rk}}\right] / \Delta \varepsilon_{1}$ equals the tangent slope of the curve. There is no definitely proportional relation between the confining pressure $\sigma_{3}$ and the extra item $v_{\text {ef }}$, so that only the relation of the age and the extra item will be considered. The value of extra item is determined as the average value under different confining pressures. For these tests, $v_{\mathrm{ef}}(7)$ equals 0.14 for $7 \mathrm{~d}$ hardfill and $v_{\mathrm{ef}}(28)$ is equal to 0.24 for $28 \mathrm{~d}$ hardfill. Due to the limited experimental results, the detailed mathematical expression can be determined as a hyperbolic function as shown:

$$
v_{e f}(\tau)=\frac{\tau \cdot V_{1}}{V_{2}+\tau}, \quad \varepsilon_{1}>\varepsilon_{1 \mathrm{~d}}
$$

where $V_{1}$ and $V_{2}$ are parameters about the features of hardfill; $\tau$ (day) is the age of hardfill material. The parameters determined from these tests are $V_{1}=0.32$ and $V_{2}=9$.

Thus

$$
v_{\mathrm{ef}}(\tau)= \begin{cases}0, & \varepsilon_{1} \leqslant \varepsilon_{1 \mathrm{~d}} \\ \frac{\tau \cdot V_{1}}{V_{2}+\tau}, & \varepsilon_{1}>\varepsilon_{1 \mathrm{~d}}\end{cases}
$$

\section{Comparison with experimental results}

The rockfill component of parallel model adopts DuncanChang hyperbolic constitutive model $[36,37]$ as an example, which uses a tangent modulus that varies with stress level as shown:

$$
E_{t}=K p_{a}\left(\frac{\sigma_{3}}{p_{a}}\right)^{n}\left[1-\frac{(1-\sin \varphi)\left(\sigma_{1}-\sigma_{3}\right)}{2 c \cos \varphi+2 \sigma_{3} \sin \varphi} R_{f}\right]^{2}
$$

The tangent Poisson's ratio could be computed as shown:

$$
v_{t}=\frac{G-F \cdot \log _{10}\left(\sigma_{3} / p_{a}\right)}{\left\{1-A^{*}\right\}^{2}}
$$

in which

$$
A^{*}=\frac{D \cdot\left(\sigma_{1}-\sigma_{3}\right)}{K p_{a}\left(\frac{\sigma_{3}}{p_{a}}\right)^{n}\left[1-\frac{(1-\sin \varphi)\left(\sigma_{1}-\sigma_{3}\right)}{2 c \cos \varphi+2 \sigma_{3} \sin \varphi} R_{f}\right]},
$$

where $K, n, c, \varphi, R_{f}, G, F, D$ are experimental parameters; $p_{a}$ is the atmospheric pressure.

According to the triaxial tests of rockfill material, parameters of rockfill component can be obtained: $K=2938 ; n$ $=0.006 ; c=4.2 \mathrm{kPa} ; \varphi=40.4^{\circ} ; R_{f}=0.90 ; G=0.29 ; F=$ $0.17 ; D=11.29$ while the atmospheric pressure is $10 \mathrm{kPa}$.

The constitutive model of cementation component and parameters are explained in sect. 3.4, and summarized in Table 3, where the first two parameters describe the features before damaging, and the latter seven parameters are associated with the mechanical behavior of cementation component after damaging.

Note that the modulus of rockfill component is a tangent form; therefore, the cementation component should use the tangent modulus correspondingly as shown:

$$
E_{\mathrm{cmt}}=\frac{\mathrm{d}\left(\sigma_{1}-\sigma_{3}\right)}{\mathrm{d} \varepsilon_{1}}=\left(1-\omega-\varepsilon_{1} \frac{\mathrm{d} \omega}{\mathrm{d} \varepsilon_{1}}\right) \cdot E(\tau) .
$$

Based on the formula of the parallel model as shown in eq. (1), letting variation $\tau$ be 7 and $28 \mathrm{~d}$, respectively, simulations of triaxial tests at these two ages can be made. A comparison between the simulation and the experimental results is shown in Figure 10 and Figure 11. Under the condition of small strain $\left(\varepsilon_{1}<2 \%\right)$, the parallel model can reflect the strain softening behavior of hardfill material approximately.

\section{Simplified method for the determination of parameters}

Parameters of the constitutive model can be determined from how the model is established. There will be a series of large-scale triaxial tests of rockfill and hardfill specimens at

Table 3 Parameters of the Cementation Component

\begin{tabular}{cccccccccc}
\hline Parameter & $M$ & $E_{0}(\mathrm{MPa})$ & $\alpha(7)$ & $\beta(7)$ & $\alpha(28)$ & $\beta(28)$ & $Q$ & $V_{1}$ & $V_{2}$ \\
\hline Value & 5.6 & 288 & $0.28 \%$ & 0.12 & $0.32 \%$ & 0.13 & 85 & 0.32 & 9 \\
\hline
\end{tabular}
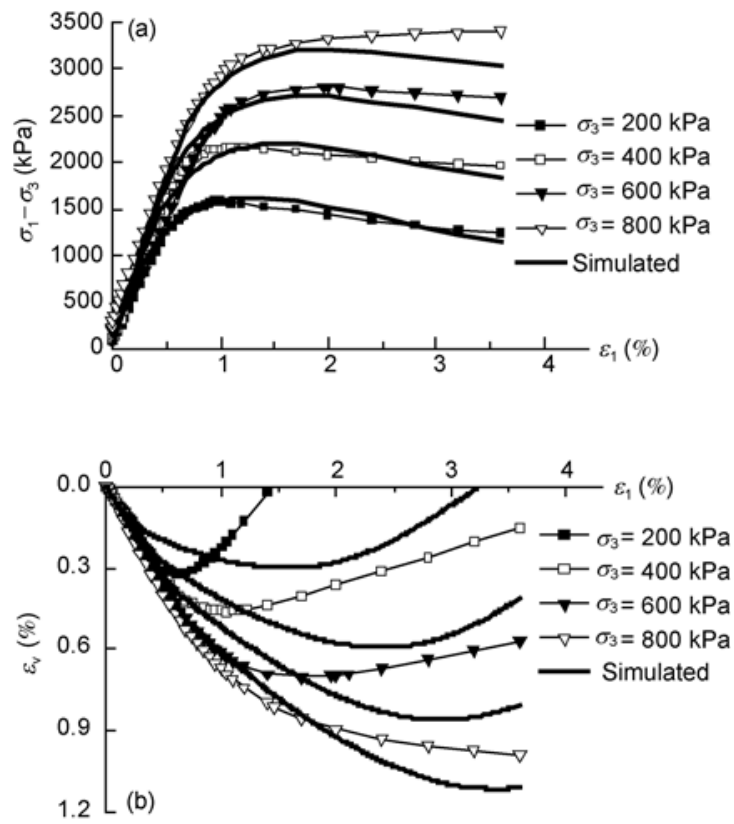

Figure 10 Comparison between the simulated and the experimental results of 7 d hardfill. (a) $\varepsilon_{1} \sim\left(\sigma_{1}-\sigma_{3}\right)$ curves; (b) $\varepsilon_{1} \sim \varepsilon_{v}$ curves. 

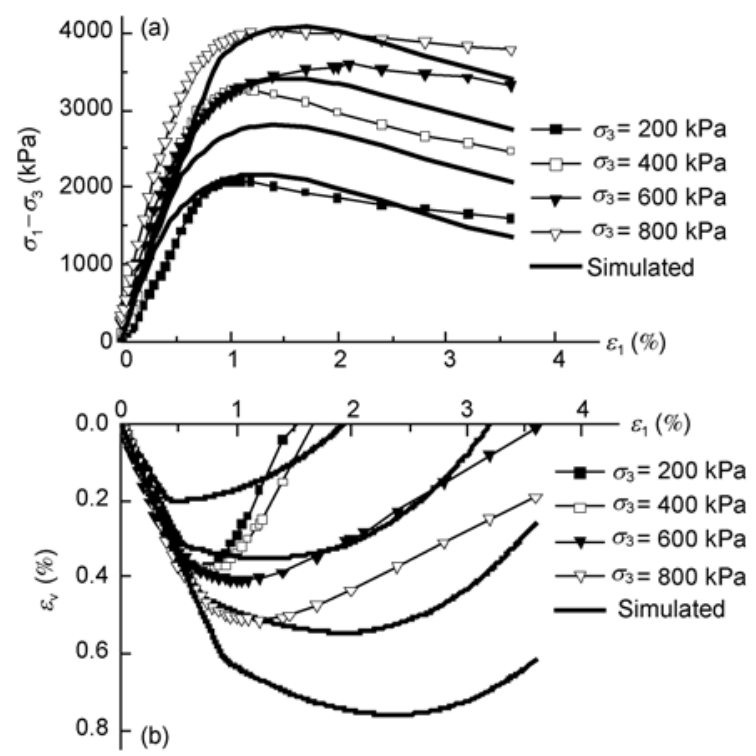

Figure 11 Comparison between the simulated and the experimental results of $28 \mathrm{~d}$ hardfill. (a) $\varepsilon_{1} \sim\left(\sigma_{1}-\sigma_{3}\right)$ curves; (b) $\varepsilon_{1} \sim \varepsilon_{v}$ curves.

different ages. However, the large-scale triaxial tests at different ages are comparatively expensive and time consuming. Because the modulus of hardfill is much greater than rockfill for the reason of cementation, the strain in a hardfill dam is much smaller than in the rockfill dam. Generally, the threshold strain may not be exceeded in most situations in dams with a height less than $100 \mathrm{~m}$. Therefore, the first two parameters of cementation component describing the features before damaging are adequate, whereas other seven parameters of cementation component related to the damaged range do not necessarily be required. According to the previous analysis, under uniaxial loading conditions, the confining pressure is zero and the cohesion of rockfill component is so small that the stress of rockfill component is also small. Thus, most stress is undertaken by cementation component and the modulus obtained by uniaxial compression tests is equal to the modulus of cementation component. Therefore, from the uniaxial tests, the two parameters in eq. (6) can be determined. One parameter $E_{0}$ represents the final elastic modulus of cementation component, and the other parameter $M$ describes the increasing function of modulus with the age.

All parameters of rockfill component can be determined by a group of triaxial tests of rockfill without cementitious material.

The friction angle $\varphi$ differs little at different ages. Therefore, the friction angle of rockfill which is considered as the initial conditions of hardfill material before being hardened can be adopted as the friction angle of hardfill. The cohesion $c(\tau)$ at different ages can be determined by multiplying the relation function of uniaxial compressive strength (shown in Figure 1) and a coefficient together. The detailed derivation is as follows.
Mohr-Coulomb strength theory shows:

$$
\left(\sigma_{1}-\sigma_{3}\right)_{f}=\frac{2 c \cos \varphi+2 \sigma_{3} \sin \varphi}{1-\sin \varphi}
$$

in which the subscript $f$ means the failure condition.

Thus, under uniaxial loading conditions, the confining pressure $\sigma_{3}$ is zero and

$$
\left(\sigma_{1}\right)_{f}=\frac{2 \cos \varphi}{1-\sin \varphi} c .
$$

It can be concluded that there is a proportional relation between uniaxial compressive strength $\left(\sigma_{1}\right)_{f}$ and cohesion. As the friction angle $\varphi$ differs little at different ages, the proportional coefficient differs little at different ages too. Thus, according to the relation $R(\tau)$ between the uniaxial compressive strength and the age, the relation $c(\tau)$ between the failure strength and the age can be calculated as shown:

$$
c(\tau)=\frac{1-\sin \varphi}{2 \cos \varphi} R(\tau)
$$

Thus, a simplified method of determination of major parameters is described by which a group of triaxial tests of rockfill material and uniaxial tests of hardfill will be carried out. The major parameters include: parameters of rockfill component, two parameters of cementation component before damaging, and Mohr-Coulomb shear strength parameters.

\section{Conclusions}

A series of large-scale triaxial tests were performed on hardfill specimens at different ages, and stress-strain behavior of hardfill was further discussed. Based on the analysis of these results, an age-related parallel constitutive model of hardfill material was then proposed, which could provide a basis for nonlinear analysis of hardfill material. Conclusions are summarized as follows.

(1) The failure strength of hardfill material follows the Mohr-Coulomb strength theory; the cohesion increases with the age of the material, whereas the friction angle keeps constant. The residual cohesion of hardfill decreases substantially compared with the peak cohesion.

(2) By subtracting stress-strain curves of rockfill from hardfill, the effect of cementation on stress-strain relationship was investigated. The influence curves of deviatoric stress show apparently linear elastic characteristic before damage occurs, and the slope of the curves and strength have a positive correlation with the age.

(3) An age-related constitutive model of hardfill is developed, which is a parallel model consisting of two components, rockfill component and cementation component. This parallel model can reflect the mechanical characteris- 
tics of both rockfill-like nonlinearity and concrete-like age relativity.

(4) A simplified method for the determination of parameters was proposed.

At the present stage, the expressions of damage are kept very simple. This part will probably require some improvement, in particular if it is necessary to describe very accurate volumetric changes. However, in consideration of the lack of laboratory study on the hardfill material, the expressions and functions of cementation component are partly assumed; hence, further research is still needed.

This work was supported partially by the National Natural Science Foundation of China (Grant No. 10932012), the China-Europe Science and Technology Cooperation Program (Grant No. 0820), and European Commission (Grant No. FP7-NMP-2007-LARGE-1).

1 Londe P, Lino M. The faced symmetrical hardfill dam: A new concept for RCC. Int Water Power Dam Constr, 1992, 44: 19-24

2 Mason P J. Hardfill and the Ultimate Dam. HRW, 2004. 26-29

3 Yang S L. Characteristics and load carrying capacity of CSG dam construction materials (in Chinese). China Civil Eng J, 2007, 40: 97103

4 Stevens M A, Linard J. The Safest Dam. J Hydraul Eng-ASCE, 2002: 139-142

5 Coumoulos D G, Koryalos T P. Lean RCC dams-laboratory testing methods and quality control procedure during construction. In: Berga L, Buil J M, Jofre C, et al. eds. Proceedings of the 4th International Symposium on Roller Compacted Concrete Dams, Madrid, Spain, 2003. 233-238

6 Capote A, Saenz F, Martin V M. Contraembalse de Moncion: a hardfill dam constructed in the Dominican Republic. In: Berga L, Buil J M, Jofre C, et al. eds. Proceedings of the 4th International Symposium on Roller Compacted Concrete Dams, Madrid, Spain, 2003. 417-420

7 Batmaz S. Cindere dam-107 m high Roller Compacted Hardfill Dam (RCHD) in Turkey. In: Berga L, Buil J M, Jofre C, et al. eds. In: Proceedings of the 4th International Symposium on Roller Compacted Concrete Dams, Madrid, Spain, 2003. 121-126

8 Mason P J, Hughes R A N, Molyneux J D. The design and construction of a faced symmetrical hardfill dam. Int J Hydropower Dams, 2008, 15: 90-94

9 Takashi Y, Yoshio O, Mikio K, et al. Application of CSG Method to Construction of Gravity Dam. In: Proceedings of 20th ICOLD Congress, Beijing, China, 2000. 989-1007

10 Isao N, Shigeharu J. 30 Years' History of Roller-compacted Concrete Dams in Japan. In: Berga L, Buil J M, Jofre C, et al. eds. In: Proceedings of the 4th International Symposium on Roller Compacted Concrete Dams, Madrid, Spain, 2003. 27-38

11 Zaniar T. Structural safety studies of Kahir dam in Iran. Middle-East J Sci Res, 2010, 6: 500-504

12 Tadahiko S. Current activities on construction and management of Dams in Japan. In: Proceedings 3rd US-JAPAN Workshop on Advanced Research on Earthquake Engineering for Dams, San Diego, USA, 2002

13 Peng Y F, He Y L. Study on application of CSG cofferdam in hydropower station construction. In: Asia-Pacific Power and Energy Engineering Conference (APPEEC) 2009, Wuhan, China, 2009. 1-4

14 He G T, Li Z F, Yu Q. Study on application of CSG material in Jie-mian measuring weir (in Chinese). In: Proceeding of the symposium on $200 \mathrm{~m}$ high RCC dams, Guangxi, China, 2006. 32-35

15 Chen Z H, Lin S Z, Wang J L, et al. Research \& application of construction technique for Hongkou dam using lean cement roll com- pacting aggregate (in Chinese). Water Power, 2008, 34: 79-81

16 Tian Y G. Rapid Construction Technology of RCC Dam (in Chinese). Beijing: China Waterpower Press, 2010. 449-474

17 Dunstan M R H. A Review of Design Criteria for High RCC Dams. In: Hansen K D, McLean F G, eds. Proceedings Roller Compacted Concrete III, ASCE, San Diego, USA, 1992. 132-147

18 Toshio H, Tadahiko F, Hitoshi Y, et al. Concept of CSG and its material properties. Berga L, Buil J M, Jofre C, et al. eds. In: Proceedings of the 4th International Symposium on Roller Compacted Concrete Dams, Madrid, Spain, 2003. 465-473

19 Tadahiko F, Akira N, Hideaki K, et al. Material properties of CSG for the seismic design of trapezoid-shaped CSG dam. In: 13th World Conference on Earthquake Engineering (WCEE), Vancouver, Canada, 2004. 391-402

20 He Y L, Peng Y F, Xiong K. Analysis on material property of hardfill dam (in Chinese). J Water Resour Archit Eng, 2007, 5: 1-6

21 Jia J S, Ma F L, Li X Y, et al. Study on material characteristics of cement-sand-gravel dam and engineering application (in Chinese). J Hydraul Eng, 2006, 37: 578-582

22 Xu J P, Wang B G, Chen G F, et al. Relation of strength with age of lean concrete for roadbase (in Chinese). J Chang'an Univ (Nat Sci), 2004, 24: 21-23

23 Lohani T N, Kongsukprasert L, Tatsuoka F, et al. Strength and deformation characteristics of cement-mixed gravel for engineering use. Benedetto H D, Doanh T, Geoffroy H, et al. eds. In: Proceedings of the 3rd International Symposium on Deformation Characteristics of Geomaterials, Lyon, France, 2003. 637-643

24 Watanabe K, Tateyama M, Jiang G L, et al. Strength characteristics of cement-mixed gravel evaluated by large triaxial compression tests. Benedetto H D, Doanh T, Geoffroy H, et al. eds. In: Proceedings of the 3rd International Symposium on Deformation Characteristics of Geomaterials, Lyon, France, 2003. 683-693

25 Kongsukprasert L, Tatsuoka F, Tateyama M. Several factors affecting the strength and deformation characteristics of cement-mixed gravel. Soils Found, JGS, 2005, 45: 107-124

26 Li Y L, Hou K J, Sun M Q, et al. Test and study on mechanical property of super-short cement concrete (in Chinese). Yellow River, 2007, 29: 59-60

27 Sun M Q, Peng C S, Li Y L, et al. Triaxial test of over lean cemented material (in Chinese). Adv Sci Tech Water Resour, 2007, 27: 46-49

28 Omae S, Sato N, Oomoto I. Dynamic properties of CSG. Berga L, Buil J M, Jofre C, et al. eds. In: Proceedings of the 4th International Symposium on Roller Compacted Concrete Dams, Madrid, Spain, 2003. 511-518

29 Li Y X, He Y L, Li Z J. Analysis of the Stress and Finite Element Stability for the Cemented Sand \& Gravel Dam (in Chinese). China Rural Water Hydropower, 2005(7): 35-38

30 Sun M Q, Yang S F, Zhang J J. Study on constitutive model for over lean cemented material (in Chinese). Adv Sci Tech Water Resour, 2007, 27: 35-37

31 Chazallon C, Hicher P Y. A constitutive model coupling elastoplasticity and damage for cohesive-frictional materials. Mech Cohes-Frict Mater, 1998, 3: 41-63

32 Vatsala A, Nova R, Murthy B R S. Elastoplastic model for cemented soils. J Geotech Geoenviron, 2001, 127: 679-687

33 Yu S W, Feng X Q. Damage Mechanics (in Chinese). Beijing: Tsinghua University Press, 1997. 10-16

34 Zhu B F. On the formula for modulus of elasticity of concrete (in Chinese). J Hydraul Eng, 1996(3): 89-91

35 Sun H, Zhao X H. Study on initial damage threshold of soft soil by true triaxial tests (in Chinese). J Hydraul Eng, 2002(7): 93-97

36 Duncan J M, Chang C Y. Nonlinear analysis of stress and strain in soils. J Soil Mech Found Div, ASCE, 1970, 96: 1629-1653

37 Kulhawy F H, Duncan J M. Stresses and movements in Oroville Dam. J Soil Mech Found Div, ASCE, 1972, 98: 653-655 